\title{
Can we meet the real need for dialysis and transplantation?
}

\author{
If money follows patients in the new NHS there should be more renal units
}

Over the past decade the profession and successive ministers of health have engaged in healthy dialogue about the level of services for dialysis and transplantation. The all party disablement group of the House of Commons has helped to bring the two sides together. Discussions were founded on early studies of the numbers of patients with end stage renal failure $^{1-3}$ and stimulated by distressing comparisons between Britain and other European countries. ${ }^{4}$ As a result an initial target for treating end stage renal failure was set at 40 new patients per million population by 1987 in England ${ }^{5}$ and at 50 per million in Wales. ${ }^{6}$ The Renal Association, concerned that achievements in Britain still lagged behind those in western Europe $^{7}$ and the United States, ${ }^{8}$ sponsored further studies of the rate of preventable death caused by renal failure. The results of two of these studies are published in this issue (pp 897, 900) ${ }^{910}$ (observations over a longer timescale in Scotland are still awaited); they suggest that the real target should be 75-80 new patients per million.

British nephrologists and renal units have hitherto been protected by "negative selection" practised by their medical colleagues $^{4}$ and still exemplified by the fates of some of the patients included in the surveys by McGeown (p 900) ${ }^{9}$ and by Feest et al (p 897). ${ }^{10}$ Plasma creatinine concentrations of $500 \mu \mathrm{mol} / \mathrm{l}$ or urea concentrations of $25 \mathrm{mmol} / \mathrm{l}$ were the entry criteria for these studies and that of the joint working party on diabetic renal failure. ${ }^{11}$ Over half of the patients who reached this degree of renal failure were either already undergoing renal replacement treatment or dead within three months. Thus patients should be referred for nephrological care before their plasma creatinine and urea concentrations reach these values. They are unlikely to have symptoms of renal failure at this stage, but failure to refer early prevents optimal preparation for dialysis and transplantation $^{10}$ and denies them the advantages of specialised care and control of blood pressure. ${ }^{12}$ In most British renal units about a third of patients arrive in end stage failure as acute uraemic emergencies. In some cases this reflects poor medical care-failure to examine the urine for albumin or to perform simple blood chemical evaluations in high risk patients such as insulin dependent diabetics and AfroCaribbean patients with hypertension.

Some years ago we suggested that the low rates of treatment in Britain were determined by the small numbers of renal units. ${ }^{13}$ Britain has 1.3 units per million; in large western European countries units tend to be smaller but there are between $4 \cdot 4$ (France) and $7 \cdot 1$ (Italy) units per million. ${ }^{7}$ In the North West Thames region referral for treatment was inversely related to the distance between patients' homes and the renal unit. ${ }^{14}$ Likewise, referral rates from centres of population without a renal unit in north Devon and Blackburn were significantly lower than those from Exeter, where there is a unit. ${ }^{10}$ Lack of facilities is accompanied by restriction in the number of specialists in renal diseases. A recent survey found 66 whole time equivalent NHS consultants and five whole time equivalent senior academic staff in nephrology in England and Wales (N F Jones for the renal disease committee of the Royal College of Physicians and the Renal Association). Thus fewer than 1.5 doctors per million population provide a service that employs five to 10 times this number of specialists in other countries. The mechanisms for rationing the treatment of end stage renal failure under the planned economy of the NHS are evident. So is the remedy, for in Wales, where three "subsidiary" renal units were opened in 1985 , the rate of acceptance of new patients rose from $34 \cdot 3$ in 1984 to 60.4 in $1987 . .^{15}$

Limited hospital treatment has forced British nephrologists to urge their patients to carry out independent dialysis, either home haemodialysis or - particularly since 1979-continuous ambulatory peritoneal dialysis, and to hope for an increased rate of kidney transplantation. Cadaveric organ donation has been helped by sympathetic publicity, ${ }^{16}$ and the United Kingdom Transplant Service, which ensures efficient distribution, has recently been given special health authority status. ${ }^{17}$ Nevertheless, suitability for these preferred means of treatment has constrained referral and selection so that older patients and those with multisystem diseases, notably diabetes, have been squeezed out of our treatment programmes. ${ }^{47}$ The British programme has been cost effective but cruel. ${ }^{18}$

All countries find treatment for end stage renal failure embarrassingly expensive, for costs do not stop at the treatments themselves. A programme for a region of four million inhabitants capable of meeting the target of 40 new patients per million population would require 45 inpatient beds-almost half the acute medical facilities of a small district general hospital. ${ }^{19}$

In the first 20 years of the NHS the patients for whom these resources are now needed would have died rapidly from uraemia. Since then the NHS service for end stage renal 
failure has been moulded by bureaucratic constraints, so that it is different in both scale and strategy from those in other relatively prosperous countries. It is also slow to respond to medical advances, which may need extra resources to make them equally available to all who could benefit, such as recombinant human erythropoietin for patients undergoing dialysis. Will the new methods of NHS funding to be introduced in 1991 change the pattern of the programme? Money that follows patients is said to make bureaucratic logjams simpler to resolve ${ }^{20}$ and it could provide an incentive for opening new renal units. The wishes of patients and the costs of transporting them to thrice weekly treatments both point to the desirability of increasing the numbers of renal units and specialists to fill geographical gaps in provision. McGeown and Feest et al have documented the real need for dialysis and transplantation. The reasons why the old style NHS has fallen short are known. Is it too much to hope that the white paper holds the key to open doors that have been held shut for too long?

A J WING

Consultant Physician

United Medical and Dental School,

St Thomas's Hospital,

London SE1 7EH

I McGeown MG. Chronic renal failure in Northern Ireland 1968-70. Lancet 1972;i:307-10

2 Pendreight DM, Heasman MA, Howitt LF, et al. Survey of chronic renal failure in Scotland. Lancet 1972;i:304-7

3 Branch RA, Clarke GW, Cochrane AL, Jones JH, Scarborough H. Incidence of uraemia and requirements for maintenance haemodialysis. Br Med f $1971 ;$; :249-54

4 Challah S, Wing AJ, Bauer R, Morris RW, Schroeder SA. Negative selection of patients for dialysis and transplantation in the United Kingdom. BrMed f 1984;288:1119-22.

5 Patton J. Kidney patients. House of Commons Official Report (Hansard) 1984 Dec 20;710:cols $309-10$

6 Edwards N. Kidney patients. House of Commons Official Report (Hansard) 1984 Dec 5;710:col 23

Wing AJ, Broyer M, Brunner FP, et al. Demography of dialysis and transplantation in Europe in 1985 and 1986: trends over the previous decade. Nephrol Dial Transplant 1988;3:714-27.

8 Rennie D, Rettig RA, Wing AJ. Limited resources and the treatment of end stage renal failure in Britain and the United States. Qf Med 1985;56:321-36.

9 McGeown MG. The prevalence of advanced renal failure in Northern Ireland. $\mathrm{Br}$ Med $\mathcal{f}$ 1990;301:900-3.

10 Feest TG, Mistry CD, Grimes DS, Mallick NP. Incidence of advanced chronic renal failure in the United Kingdom and the need for end stage renal replacement treatment. $\mathrm{Br}$ Med $\mathrm{J}$ 1990;301:897-900.

11 Joint Working Party. Treatment of and mortality from diabetic renal failure in patients identified in the 1985 United Kingdom survey. Br Med f 1989;299:1135-6.

12 Bergstrom J, Alverstrand A, Bucht $\mathrm{H}$, Gutierrex A. Progression of chronic renal failure in man is retarded with more frequent clinical follow-up and better blood presssure control. Clin Nephrol 1986;25:1-6.

13 Wing AJ. Why don't the British treat more patients with kidney failure? BrMed $\mathcal{F} 1983 ; 287: 1157-8$

14 Dalziel $M$, Garrett $C$. Intraregional variation in treating end stage renal failure. Br Med $\mathcal{J}$ 1987;294:1382-3.

15 Smith WGJ, Cohan DR, Asscher AW. Evaluation of renal services in Wales with particular reference to the role of subsidiary renal units; report to the Welsh office 1989. Cardiff: KRUF Institute of Renal Disease, Royal Infirmary, 1989.

16 Feest TG, Riad HN, Collins CH, Golby MGS, Nicholls AJ, Hamad SN. Protocol for increasing organ donation after cardiovascular deaths in a district general hospital. Lancet 1990;335:1133-5. Department of Health. Special health authority to manage UK Transplant Service. London:DoH, 1990. (Press release, 11 th June 1990 .) 18 Halper T. The misfortunes of others: end stage renal disease in the United Kingdom. Cambridge:

19 Wood IT, Mallick NP, Wing AJ. Prediction of resources needed to achieve the national target for the treatment of renal failure. Br Med $\mathcal{F}$ 1987;294:1467-70.

20 Dorrell S. Kidney patients. House of Commons Official Report (Hansard) 1990 May 24;173:cols $434-42$

\section{The pelvic ileal reservoir: apocalypse later?}

\section{Patients need monitoring for the long term effects of reservoir construction}

The construction of a pelvic ileal reservoir with ileoanal anastomosis was first proposed as an alternative to permanent ileostomy and continent ileostomy in patients undergoing proctocolectomy for ulcerative colitis.' ${ }^{\prime}$ Ulcerative colitis remains the most common indication, but the operation has also become an effective alternative to total colectomy and ileorectal anastomosis for familial adenomatous polyposis and has been used in patients with functional bowel disorders such as chronic megacolon and idiopathic constipation. The procedure is now considered a safe and satisfactory alternative to permanent ileostomy ${ }^{2}$ : most suitable patients accept the offer of a pelvic reservoir rather than a.permanent ileostomy. ${ }^{3}$

Even so, the creation of the reservoir is not without complications. The altered intraluminal environment in the reservoir has a profound effect on the ileal mucosa, producing chronic inflammation and varying degrees of villous atrophy. ${ }^{+}$ These inflammatory and architectural changes result in an appearance of colonic metaplasia. ${ }^{+5}$ The evidence for colonic metaplasia is further substantiated by histochemical studies of mucin $^{+}$and by the acquisition of immunoreactivity for putative colon specific monoclonal antibodies. ${ }^{67}$ The inflammatory and metaplastic alterations occur in the reservoirs of patients with both ulcerative colitis and familial adenomatous polyposis and probably represent an adaptive response of the mucosa to the altered intraluminal environment. The ileal mucosa of experimental animal models shows similar metaplastic changes after reservoir construction. ${ }^{89}$

One of the more severe long term complications of the reservoir is the active chronic inflammatory condition known as pouchitis. There is much confusion and controversy surrounding pouchitis, mainly because the term has not been tightly defined. ${ }^{10}$ Several heterogeneous mechanisms, including mucosal ischaemia, ${ }^{7112}$ mucosal prolapse, ${ }^{+}$and Crohn's disease ${ }^{11}$ may cause inflammation in the reservoir, and all have been called pouchitis. This confusion accounts for the large divergence in prevalence rates in large series$7 \%$ to $42 \% .^{10}$ The definition of pouchitis should include clinical (painful increase in stool frequency, urgency, systemic symptoms), endoscopic (increased vascularity, bleeding, ulceration), and histopathological (acute inflammation, ulceration, chronic changes) criteria. ${ }^{11}{ }^{12}$ These criteria define a condition that occurs in about $10-20 \%$ of patients with ileal reservoirs. ${ }^{11} 1{ }^{14}$ Clinically, this syndrome is a relapsing and remitting chronic disease with a variable but often favourable response to antibiotics (particularly metronidazole) and to sulphasalazine or steroids, or both. Despite the undoubted response of many patients with pouchitis to metronidazole no consistent bacteriological changes have been observed in the reservoirs of these patients ${ }^{51+16}$ : the response to metronidazole may relate to its immunosuppressive properties. Stasis and bacteriological changes are probably a prerequisite for the morphological changes in the mucosa of the reservoir, and pouchitis may then supervene in susceptible individuals.

Although the cause of pouchitis is obscure, it seems to be closely linked to ulcerative colitis. Similar associations have been observed in the ileitis that complicates continent ileostomy reservoirs. ${ }^{11} 17$ In most large series pouchitis, when adequately defined, is more common in patients with ulcerative colitis than in those with familial adenomatous polyposis, ${ }^{1011}$ and indeed may well be restricted to them. Acute inflammation in the reservoir mucosa, with and without pouchitis, is much more prevalent in patients with ulcerative colitis than in those with familial adenomatous polyposis, ${ }^{+18}$ and similar distributions of immunoglobulin subtypes within intramucosal plasma cells have been shown in the reservoir of patients with pouchitis as in the colonic mucosa of patients with colitis. ${ }^{19}$ In both pelvic reservoirs and continent ileostomies pouchitis is associated with the development of conditions such as arthritis, iridocyclitis, and pyoderma gangrenosa, which are characteristic extracolonic manifestations of idiopathic inflammatory bowel disease. ${ }^{2021}$ Patients with extensive colitis at proctocolectomy are more likely to develop pouchitis than those with more restricted disease, ${ }^{22}$ although there is no relation between backwash ileitis and pouchitis. ${ }^{23}$ 